\title{
CELLULOSE FOR MEDICAL APPLICATIONS: PAST, PRESENT, AND FUTURE
}

\author{
Nicholas Hoenich $^{\mathrm{a}}$
}

Films and tubes manufactured from cellulose have historically been used in the treatment of renal failure, but their use for this purpose has declined in recent years in favour of films manufactured from synthetic material blends. As the clinical application of cellulose for dialysis declines, new applications for its use are emerging, of which the most promising appears to be the use of microbial cellulose synthesized by Acetobacter xylinum as a novel wound healing system and as a scaffold for tissue regeneration.

Keywords: Cellulose, Modified cellulose, Cellulose acetate, Films, Tubes, Dialysis, Haemodyalysis, Tissue scaffolds, Wound care, Microcapsules, Sutures, Implants

Contact information: a: School of Clinical Medical Sciences, Newcastle University, Newcastle upon Tyne NE2 4HH; nicholas.hoenich@ncl.ac.uk

\section{HISTORICAL OVERVIEW}

Cellulose is a naturally occurring material found in wood, cotton, hemp, and other plant-based materials, and consists of repeating anhydroglucose units joined by $\beta-(1,4)$ linkages, forming the basic repeating unit. It was first isolated from wood in 1885 by Charles F. Cross and Edward Bevan at the Jodrell Laboratory of the Royal Botanic Gardens, Kew, London. The process for manufacturing cellulose film from viscose was discovered by three English chemists, Charles Frederick Cross, Edward John Bevan and Clayton Beadle in 1898. However it was not until 1913 that Dr Jacques Brandenberger developed thin transparent cellulose film into commercial production at the 'La Cellophane SA factory in Bezons, France.

Although the primary use of cellulose films has been for wrapping purposes, it has also found an application in the treatment of renal failure, as well as in a variety of more recent and evolving clinical applications such as for scaffolds in tissue engineering, temporary skin substitute, a haemostatic agent, post operative adhesion barrier, and as a culture material for hepatocytes. discussed.

In this paper, the use of cellulose in medical applications are reviewed and

\section{Cellulose for Use in the Treatment of Renal Failure}

When the human kidney fails, either as a consequence of disease (chronic renal disease) or following traumatic injury, or the ingestion of poisons, the blood-borne metabolites of protein break down, water that would normally be handled by the kidney accumulates, and supportive therapy is required to sustain life. The most widely used treatment is haemodialysis, with over 1.1 million persons receiving such treatment 
worldwide in 2002 (Lysaght 2002). Haemodialysis refers to the dialysis of blood, during which the patient's blood is passed through an artificial kidney or haemodialyser, containing a membrane. Blood flows on one side of the membrane, whilst the other side is bathed by an electrolyte or salt solution (dialysis fluid) continually produced by a proportionating system (the artificial kidney machine), which also monitors and controls treatment. Molecules small enough to pass through the membrane, such as salts and low molecular protein breakdown products, tend to move in the direction of decreasing concentration. Larger substances, such as proteins and cells having dimensions greater than the pore diameter, are retained. Haemodialysis is generally performed three times weekly for patients with irreversible renal or kidney failure, whilst the treatment regimens for acute or reversible renal failure are governed by clinical requirements and may include intermittent or continuous treatment over a period of several days.

Although diffusion is the primary driving force within the dialyser for solute transport, other mechanisms, such as convection, a consequence of fluid flux across the membrane, and adsorption to the membrane, also make small contributions, and both have been developed to provide therapies for specific groups of patients (Rabindrahath et al. 2006).

The term dialysis was coined by Thomas Graham, Professor of Chemistry at Anderson's University in Glasgow. In 1861 his experiments demonstrated that crystalloids were able to diffuse through vegetable parchment coated with albumin (which acted as a semi-permeable membrane; Gottschalk et al. 1997). Although Graham predicted that his findings might be applicable to medicine, he did not venture into this area. The first historical description of dialysis was published in 1913 when Abel, Rowntree and Turner "dialyzed" anesthetized animals by directing their blood outside the body and through tubes of semi-permeable membranes (Abel et al. 1990). These early membranes were made from a mixture of cotton and sulphuric and nitric acids, which were dissolved in alcohol. The tubes, which were connected at either end to a glass manifold to receive and return the blood, were approximately $8 \mathrm{~cm}$ in length and were encased in a glass cylinder through which the dialysis fluid passed. The tubes were in many respects similar to the hollow fibre designs in use today. Such membranes were difficult to produce and sterilise, and were subject to leakage and lacked consistency in pore size.

In 1925 Erwin O. Freund in Chicago discovered that he could make a sausage casing based on cellulose by the use of the viscose process. The cellulose was dissolved in alkali, producing a viscose solution, which when extruded into an acid bath converts the viscose into cellulose. This material became known as Visking tubing (Visking Corporation Chicago, Ill, USA). In the same year in Europe, Kalle Ag (Wisebaden, Germany) began the production of Cellophane, and this material was used in the early treatments of acute or reversible kidney failure by Kolff in the Netherlands in the 1940s (Jacobze et al. 2005). For such treatments a long cellophane tube spirally wrapped around a cylinder and rotated in a stationary dialysis fluid bath was used. The method was subsequently developed by Kolff and Berk, and became the first apparatus in widespread clinical use (Kolff et al. 1997).

The widespread application of haemodialysis for the treatment of renal failure became a possibility with the availability of robust methods to gain access to the patients' circulation (Konner 2005). In parallel with this, several new designs of artificial kidney, 
including the coil, parallel flow and the hollow fibre dialysers became available. Early variants of such dialysers used membranes based on cellulose. Worldwide, the largest producer of membranes suitable for use in the coil and parallel plate designs was J. P. Bemberg AG (Wuppertal, Germany ), who produced the membranes by the solubilisation of cellulose in an ammonia solution of cupric oxide (cuprammonium process). The original variant of the hollow fibre dialyser utilized cellulose acetate as the membrane, which was produced by the Dow Chemical company and originally used for desalination applications (Gotch et al. 1969). European production of hollow fibres based on cellulose began some years later in 1974.

Clinical use of the coil dialysers has declined, but parallel plate devices such as those shown in Fig. 1 continue to be used. The majority of patients today receive their treatment using a hollow fibre dialyser (Fig. 2). In such devices, which are available in a range of surface areas to meet differing clinical requirements, the hollow fibres have internal diameters within the range 180-220 $\mu \mathrm{m}$ and wall thicknesses between 6 and 15 $\mu \mathrm{m}$.

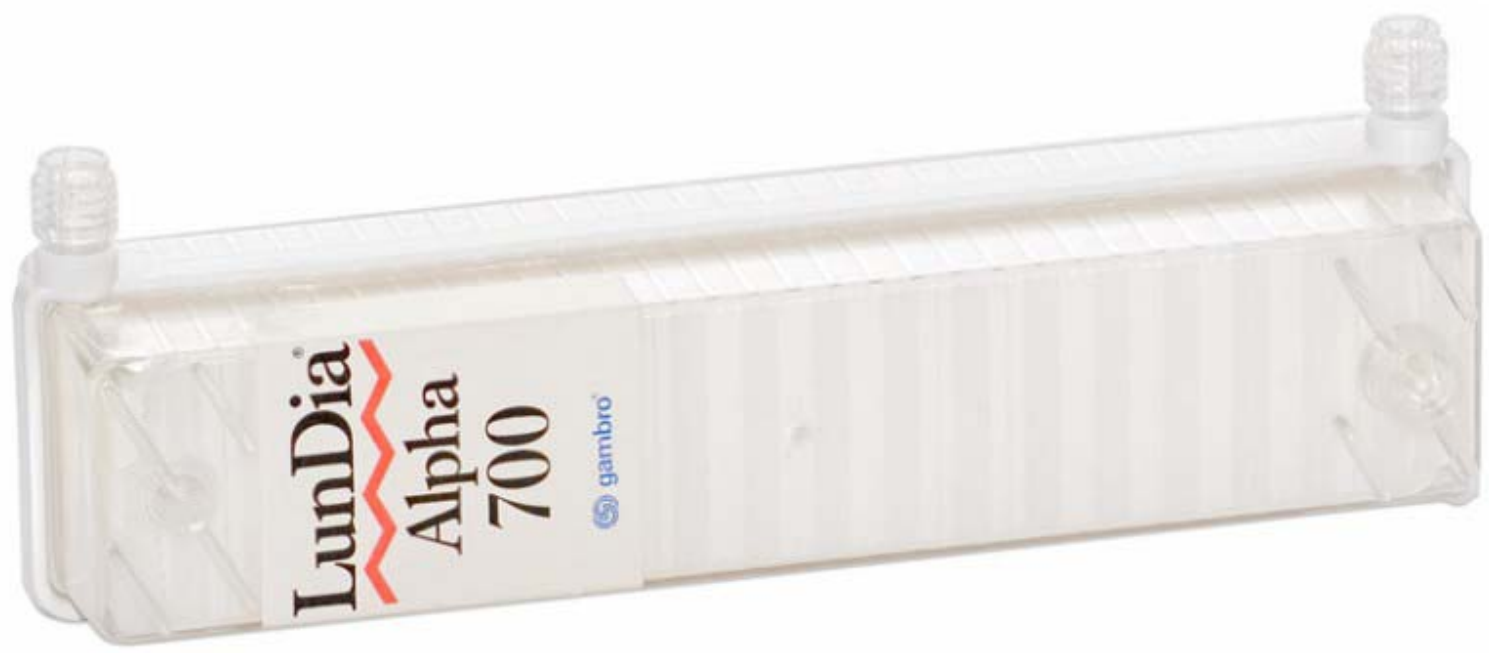

Fig. 1. Plate type dialyser utilizing sheet membranes supported on extruded polypropylene plates [Illustration courtesy of Gambro Ab, Lund, Sweden]

\section{CONTEMPORARY ISSUES}

Concerns began in the 1970s regarding the narrow range of molecules that could be removed by cellulose membranes. These concerns led to the development of membranes with an open-pored structure and new treatment techniques such as haemodiafiltration, a process in which whole blood is first diluted with physiologic electrolyte solution and then ultrafiltered across a membrane (Henderson et al. 1970). Since there were no cellulose-based membranes commercially available at that time that could meet the requirements of haemodiafiltration or haemofiltration, the procedure utilized membranes manufactured from synthetic polymer blends, such as the polysulfone membrane developed by the Amicon Corporation. These membranes were highly 
permeable, yielding high filtration rates at low transmembrane pressures. Furthermore, they could be fabricated to provide good size selectivity, with a molecular cutoff of ca. $50,000 \mathrm{Da}$. Subsequent modifications of the manufacturing process of cellulose-based membranes have meant that today cellulose membranes are available for use in these therapies.

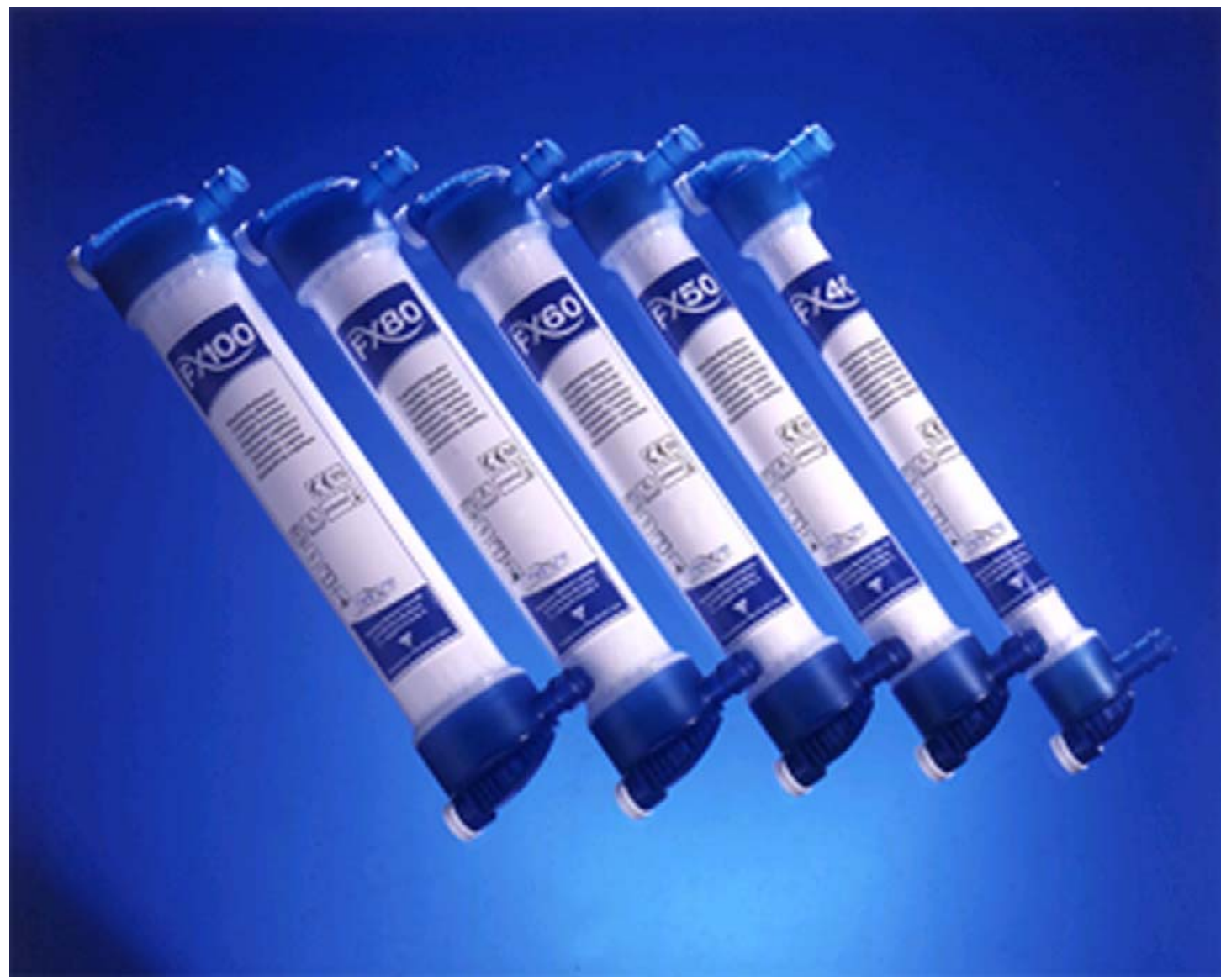

Fig. 2. Contemporary hollow fibre dialysers are available in a variety of sizes to meet differing clinical treatment requirements [Illustration courtesy of Fresenius Medical care, Bad Homburg, Germany.

In contrast to cellulose-based membranes, membranes manufactured from synthetic copolymers were associated with a reduced lecopaenia, or a transient loss of leucocytes from the circulation (Woffindin and Hoenich 1988). Subsequent research indicated that the leucopaenia was a consequence of pulmonary sequestration of the cells mediated by the contact of blood with the membrane surface (Craddock et al. 1977). It is now well accepted that C3a, C5a, and the terminal complement complex (TCC) stimulate the expression of receptors on leucocytes, leading to aggregation and sequestration in the pulmonary microvasculature (Dhondt et al. 1998). The desire to minimize these responses resulted in the modification of the classical cellobiose unit of the cellulose strands in which the $\mathrm{OH}$ groups are either replaced or the blood contacting surface is coated by materials such as poly-ethylene glycol (PEG) to minimize blood exposure to the hydroxyl groups on the surface (see Fig. 3 and Table 1). 


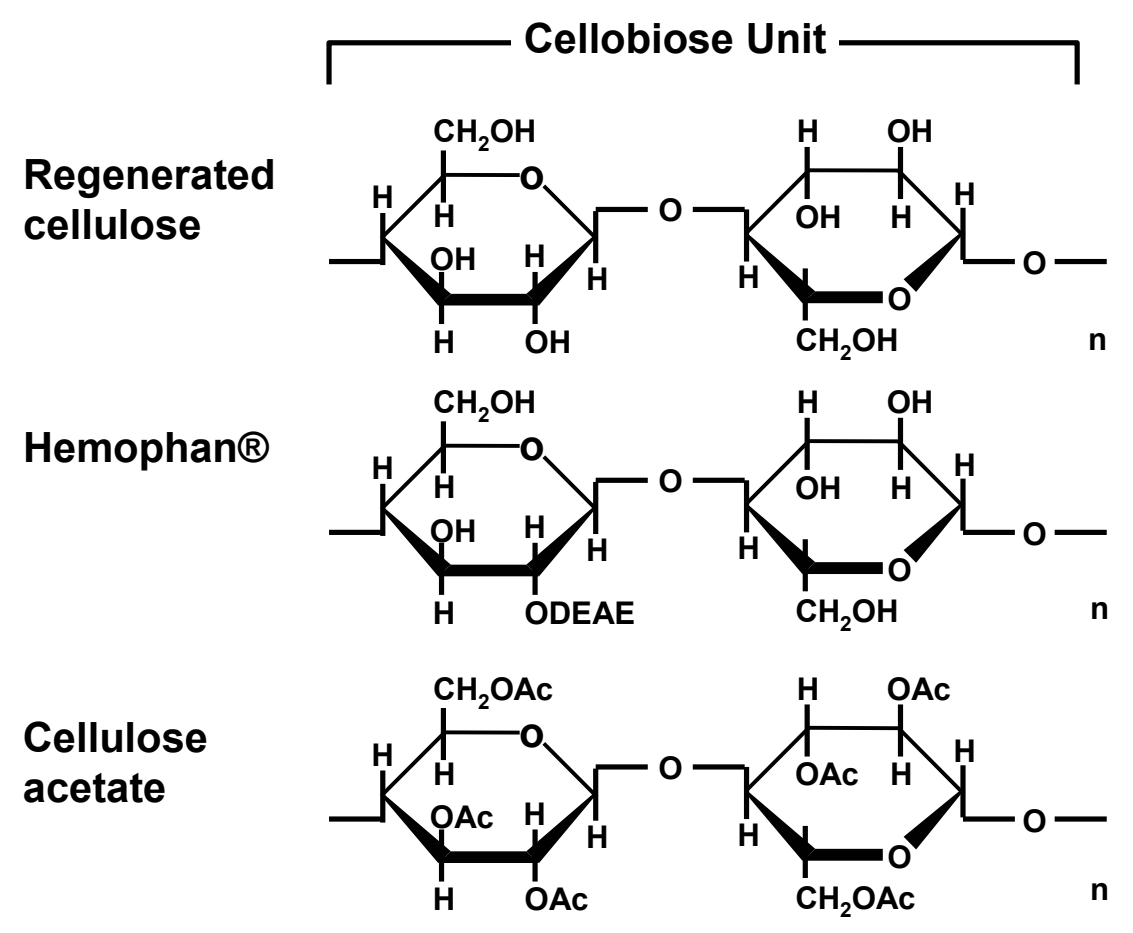

Fig. 3. The chemical structure of cellulose membranes showing partial modification of the $\mathrm{OH}$ groups. [DEAE $=$ diethylaminoethyl; $A c=$ acetyl]

Table 1. Cellulose based Haemodialysis Membranes

\section{Cuprammonium rayon \\ Cuprophan $^{\mathrm{TM}}$ \\ Hemophan $^{\mathrm{TM}}$ \\ Excerbane $^{\mathrm{TM}}$ \\ PEG modified cellulose \\ SMC $^{\text {TM }}$ \\ Cellulose acetate \\ Cellulose tri-acetate \\ Cellulose 2.5 acetate}

\author{
Regenerated cellulose (unmodified) \\ Regenerated cellulose (unmodified) \\ Cellulose etherified with dimethylaminoethyl DEAE \\ Regenerated cellulose coated with Vitamin E \\ Cuprammonium rayon coated with poly ethylene glycol \\ (PEG) \\ Synthetically modified cellulose in which there is benzyl \\ group substitution of the hydroxyl groups \\ Regenerated cellulose esterified with acetate \\ Regenerated cellulose esterified with 3.0 acetate \\ Regenerated cellulose esterified with 2.5 acetate
}

Membranes were historically considered as inert phase separators; however, repeated blood contact takes place with the dialysis membrane, which typically has an area of $1-1.5 \mathrm{~m}^{2}$. This contact results not only in the activation of the body's humoral and cellular processes, but may also play a role in the outcomes associated with dialysis treatment. It is now recognised that patients receiving dialysis are subject to oxidative stress associated with the dialysis treatment, which contributes to the pathogenesis of 
vascular injury and in the progression of atherosclerosis (Himmelfarb 2005). To minimize the activation of polymorphonuclear leukocytes on the surface of dialysis membranes, a vitamin E-coated cellulose membrane has recently been produced, which reduces oxidative stress induced by the treatment (Galli et al. 1998).

In the artificial kidney, the membrane acts as a semi-permeable barrier, separating the sterile blood side from the non-sterile dialysis fluid. Within the dialysis fluid, potential exists for bacterial contamination and the formation of biofilm in the dialysis machine or in the distribution systems delivering water to the dialysis machines (Tapia and Yee 2006). Bacteria, due to their size, cannot cross the membrane, but bacterial fragments or endotoxins are able to do so, and this has raised concerns that membranes with a large pore size may confer a risk to the patient of exposure to cytokine-inducing bacterial substances in the dialysate, contributing to the microinflammatory state of patients undergoing regular dialysis (Yao et al. 2004).

Membranes manufactured from cellulose are a homogenous gel, but membranes manufactured from polymer blends have a more complex structure. Several studies have reported higher transfer of cytokine-inducing bacterial substances through low-flux cellulosic compared to high-flux synthetic membranes (Weber et al. 2004a). This surprising paradox is explained by adsorption of cytokine-inducing bacterial substances to synthetic membranes (Hayamaa et al. 2003).

\section{Other Medical Applications of Cellulose}

\section{Wound care}

If a wound is to heal effectively, it must be maintained in a wet condition. The best dressing is the patient's own skin, which is permeable to vapour and protects the deeper layer tissue against mechanical injuries and infection. For many years biological dressings of pig skin or human cadaver skin have been used, but such products are expensive and may only be used for a short period.

Microbial cellulose synthesized by Acetobacter xylinum shows considerable potential as a novel wound healing system, resulting from its unique nanostructure. During the process of biosynthesis, various carbon compounds of the nutrition medium are utilized by the bacteria, then polymerized into single, linear $\beta$-1,4-glucan chains and finally secreted outside the cells through a linear row of pores located on their outer membrane. The subsequent assembly of the $\beta$-1,4-glucan chains outside of the cell is a precise, hierarchical process. Initially, they form sub-fibrils (consisting of 10-15 nascent $\beta$-1,4-glucan chains), then later micro-fibrils, and finally bundles of micro-fibrils consisting of a loosely wound ribbon. The thick, gelatinous membrane formed is characterized by a 3-D structure consisting of an ultrafine network of cellulose nanofibres (3-8nm) which are highly uniaxially oriented have a high cellulose crystallinity (60$80 \%$ ) and mechanical strength.

The first efforts to commercialize microbial cellulose on a large scale were initiated by Johnson \& Johnson in the early 1980s. The patents arising from this work were subsequently licensed to Xylos, a company responsible for the manufacture of The $\mathrm{XCell}{ }^{\circledR}$ family of wound-care products. 
A number of other commercial and academic institutions are developing this material. A Brazilian company, BioFill Produtos Bioetecnologicos (Curitiba, PR Brazil), produces a range of products based on this material, including Biofill ${ }^{\circledR}$ and Bioprocess ${ }^{\circledR}$ (used in the therapy of burns, ulcers as temporary artificial skin), and Gengiflex ${ }^{\circledR}$ (applied in treatment of periodontal diseases; Fontana et al. 1990).

Several Japanese companies and national governmental organizations have collaborated to set up interdisciplinary research programs, whilst the Technical University of Lodz in Poland has undertaken basic research studies on cellulose biosynthesis (Czaja et al. 2006).

A number of questions concerning this material remain unresolved. First, there is no clear indication as to its mechanisms of action, which is most likely to be a result of its unique nanostructure, creating optimal moist conditions for wound healing and skin regeneration. Production factors influencing its mode of action remain undefined, and the availability of large-scale, efficient fermentation for production is lacking.

\section{Encapsulation}

Activated charcoal is effective for the direct removal of various circulating toxic materials and waste metabolites from the blood (haemoperfusion). It may be used in the treatment of poisonings, as well as a bridge to liver transplantation, and occasionally in acute liver failure until the liver regenerates (in conjunction with other treatment modalities). The use of uncoated charcoal, however, is associated with adverse effects, such as hypotension and the appearance of platelet aggregates in the circulation, as well as particulate release. Coating of the material results in an improved biocompatibility, and a variety of coatings, including cellulose nitrate have been used (Chang 1984).

Materials other than charcoal, as well as cells may be encapsulated for a variety of clinical applications. Cellulose acetate butyrate microcapsules, as well as cellulose-based microspheres, have been used for the delivery of drugs (Lin and Wu 1999; Weber et al. 2004b; Fundueanu et al. 2005; Zhou et al. 2005). More recently, this approach has been extended to bovine spermatozoa (Weber et al. 2006).

Acute renal failure frequently occurs following sepsis. The removal of endotoxins by extracorporeal adsorption processes is a promising approach to the treatment of Gram-negative sepsis and endotoxin shock. Microspheres manufactured by coating a cellulose matrix with polyethyleneimine have demonstrated high adsorptive capacity for endotoxins (Weber et al. 1995; Fang et al. 2004; Taniguchi et al. 2006).

\section{Cellulose as an implant material}

Sutures are the largest group of devices implanted into humans. Silk is a traditional fiber used as sutures in medical applications. Although biodegradable, its major disadvantage is its lower tensile strength and reaction with tissues. The problem of strength retention in the case of bio-absorbable commercial sutures is being tackled by different surface modification techniques. Polypropylene and polyester filament coated with Teflon, for example, are employed for vascular surgery. Sutures by the modification of cellulose filaments also have been produced. Carbon fiber based sutures also have been produced by the modification of cellulose filaments (Narat et al. 1950). 
Bacterial cellulose derived from Acetobacter xylinum has an ultrafine network architecture, high hydrophilicity, and mouldability during formation. In addition to the applications discussed, it is also suitable for use in micronerve surgery and as an artificial blood vessel suitable for microsurgery. Such products in the form of BActerisal Synthesized Cellulose (BASYC®) have been described in the literature (Klemm et al. 2001).

Haemorrhage continues to be a serious complication of surgical procedures. Surgicel ${ }^{\circledR}$ (oxidized regenerated cellulose) is used widely to control haemorrhage, as this material, when saturated with blood, swells rapidly (Sharma et al. 2003).

One of the goals of tissue engineering is to manufacture scaffolds, suitable for transplantation, which are infiltrated with cells. Both viscose cellulose sponges and nonwoven cellulose have been used experimentally to fabricate cartilage transplants (Pulkkinen et al. 2006; Muller et al. 2006). Cellulose derived from Acetobacter xylinum, as discussed above in the context of wound healing, has also been explored as a potential scaffold material, due to its unusual material properties and degradability (Svensson et al. 2005).

\section{THE FUTURE}

The most widely used application of cellulose in medicine has been as a membrane in the treatment of renal failure. Worldwide trends in the use of membranes for the treatment of chronic renal failure indicate a move away from cellulose-based membranes in favour of synthetic membranes (Grassmann et al. 2005).

There are many reasons for this trend. But an important question is whether patients treated with cellulose membranes are at a disadvantage, compared to patients receiving treatment using synthetic membranes, in terms of outcomes and wellbeing. Historic studies suggested that this may have been the case, but a recent Cochrane review found no evidence of benefit when synthetic membranes were compared with cellulose membranes or modified cellulose membranes in terms of reduced mortality or the reduction in dialysis-related adverse symptoms (Macleod et al. 2005). Despite this review, the European Best practice guidelines suggest that dialyser membranes with the lowest degree of complement and leukocyte activation should be applied. Dialyser membranes that induce strong complement and leukocyte activation, inflammatory reactions, and/or a blunting of the response of leukocytes to stimuli should be avoided (Anon. 2002). This set of practices certainly precludes the continuing use of unmodified cellulose membranes. Discontinuation of the use of modified cellulose membranes in favour of synthetic membranes is, however, less compelling, since such membranes overlap in terms of their biocompatibility with those manufactured from synthetic materials (Hoenich et al. 1995). Furthermore, there may be other factors, such as cost, favouring the continuing use of such membranes in emerging economies.

As the clinical application of cellulose in the form of membranes for dialysis declines, new applications are emerging. Of these, the most promising appears to be the use of microbial cellulose synthesized by Acetobacter xylinum as a novel wound healing system. 


\section{REFERENCES CITED}

Abel, J. J., Rowntree, L. G., and Turner, B. B. (1990). "On the removal of diffusable substances from the circulating blood by means of dialysis," Trans. Assoc. Amer. Physicians, 1913. Transfus Sci. 11, 164-165.

Anon. (2002). "European Best Practice Guidelines Expert Group on Hemodialysis, European Renal Association. Section III. Biocompatibility," Nephrol. Dial. Transplant. 17(Suppl. 7), 32-44.

Chang, T. M. (1984). “Coated charcoal haemoperfusion," Life Support Syst. 2, 99-106.

Craddock, P. R., Fehr, J., Dalmasso, A. P., Brighan, K. L., and Jacob, H. S. (1977). "Hemodialysis leukopenia. Pulmonary vascular leukostasis resulting from complement activation by dialyzer cellophane membranes," J. Clin. Invest. 59, 879888.

Czaja, W., Krystynowicz, A., Bielecki, S., and Brown, R. M., Jr. (2006). "Microbial cellulose - The natural power to heal wounds," Biomaterials 27, 145-151.

Dhondt, A., Vanholder, R., and Lameire, N. (1998). "Hemodialysis-related bioincompatibility and adhesion molecules," Int. J. Artif. Organs. 21, 501-505.

Fang, H., Wei, J., and Yu, Y. (2004). "In vivo studies of endotoxin removal by lysinecellulose adsorbents," Biomaterials 25, 5433-5440.

Fontana, J. D., de Sousa, A. M., Fontana, C. K, Torriani, I. L., Moreschi, J. C, Gallotti, B. J., et al. (1990). "Acetobacter cellulose pellicle as a temporary skin substitute," Applied Biochem. Biotech. 4/25, 253-264.

Fundueanu, G., Constantin, M., Esposito, E., Cortesi, R., Nastruzzi, C., Menegatti, E. (2005). "Cellulose acetate butyrate microcapsules containing dextran ion-exchange resins as self-propelled drug release system." Biomaterials 26, 4337-4347.

Galli, F., Rovidati, S., Chiarantini, L., Campus, G., Canestrari, F., and Buoncristiani, U. (1998). "Bioreactivity and biocompatibility of a vitamin E-modified multi-layer hemodialysis filter," Kidney Int. 54, 580-589.

Gotch, F., Lipps, B., Weaver, J., Jr, Brandes, J., Rosin, J., Sargent, J., and Oja, P. (1969). "Chronic hemodialysis with the hollow fiber artificial kidney (HFAK)," Trans. Amer. Soc. Artif. Intern. Organs 15, 87-96.

Gottschalk, C. W, and Fellner, S. K. (1997). "History of the science of dialysis," Amer. J. Nephrol. 17, 289-298.

Grassmann, A., Gioberge, S., Moeller, S., and Brown, G. (2004). "ESRD patients in 2004: Global overview of patient numbers, treatment modalities and associated trends," Nephrol. Dial. Transplant. 20, 2587-2593.

Hayamaa, M., Miyasakab, T., Mochizukic, S., Asaharab, H., Yamamotoa, K., Kohoria, F., Tsujiokab, K., and Sakai. K. (2003). "Optimum dialysis membrane for endotoxin blocking," J. Membrane Sci. 219, 15-25.

Henderson, L. W., Ford, C., Colton, C. K., Bluemle, L. W., and Bixler, H. J. (1970). "Uremic blood cleansing by diafiltration using a hollow fiber ultrafilter," Trans. Amer. Soc. Artif. Intern. Organs. 16, 107-112. 
Himmelfarb, J. (2005). "Relevance of oxidative pathways in the pathophysiology of chronic kidney disease," Cardiol. Clin. 23, 319-330.

Hoenich, N. A., Woffindin, C., Mathews, J. N., and Vienken, J. (1995).

"Biocompatibility of membranes used in the treatment of renal failure," Biomaterials $16,587-592$.

Jacobze, J. W. (2005). "Kolff and Kampen," ASAIO J. 51(3), 309-311.

Klemm, D., Schumann, D., Udhard, U., and Marsch, S. (2001). "Bacterial synthesized cellulose - Artificial blood vessels for microsurgery," Prog. Polymer Sci. 26, 15611603.

Kolff, W. J., Berk, H. T. J., ter Welle, M., van der Ley, A. J., van Dijk, E. C., and van Noordwijk, J. (1997). "The artificial kidney: A dialyser with a great area," 1944. J Am Soc Nephrol. 8(12), 1959-1965.

Konner, K. (2005). "History of vascular access for haemodialysis," Nephrol. Dial. Transplant. 20, 2629-2635.

Lin, W. J., and Wu, T. L. (1999). "Modification of the initial release of a highly watersoluble drug from ethyl cellulose Microspheres," J. Microencapsul. 16, 639-646.

Lysaght, M. J. (2002). "Maintenance dialysis population dynamics: Current trends and long-term implications," J. Amer. Soc. Nephrol. 2002 (Suppl 1), S37-S40.

Macleod, A. M., Campbell, M., Cody, J. D., Daly, C., Donaldson, C., Grant, A., Khan, I., Rabindranath, K. S., Vale, L., and Wallace, S. (2005). "Cellulose, modified cellulose and synthetic membranes in the haemodialysis of patients with end-stage renal disease," Cochrane Database Syst. Rev. 20, CD003234.

Muller, F. A., Muller, L., Hofmann, I., Greil, P., Wenzel, M. M., and Staudenmaier, R. (2006). "Cellulose-based scaffold materials for cartilage tissue engineering," Biomaterials 27, 3955-3963.

Narat, J. K., Cipolla, A. F., and Cangelosi, J. P. (1950). "Fortisan (regenerated cellulose yarn), a new suture material," Arch. Surg. 60, 1218-1230.

Pulkkinen, H., Tiitu, V., Lammentausta, E., Hamalainen, E. R., Kiviranta, I., and Lammi, M. J. (2006). "Cellulose sponge as a scaffold for cartilage tissue engineering," Biomed. Mater. Eng. 16(Suppl 4): S29-S35.

Rabindranath, K. S., Strippoli, G. F., Daly, C., Roderick, P. J., Wallace, S., and MacLeod, A. M. (2006). "Haemodiafiltration, haemofiltration and haemodialysis for end-stage kidney disease," Cochrane Database Syst. Rev. 4CD006258.

Sharma, J. B., Malhotra, M., and Pundir, P. (2003). "Laparoscopic oxidized cellulose (Surgicel) application for small uterine perforations," Int. J. Gynaecol. Obstet. 83, 271-275.

Svensson, A., Nicklasson, E., Harrah, T., Panilaitis, B., Kaplan, D. L., Brittberg, M., and Gatenholm, P. (2005). "Bacterial cellulose as a potential scaffold for tissue engineering of cartilage," Biomaterials 26, 419-431.

Tapia, G., and Yee, J. (2006). "Biofilm: Its relevance in kidney disease," Adv. Chronic Kidney Dis. 13, 215-224.

Taniguchi, T., Hirai, F., Takemoto, Y., Tsuda, K., Yamamoto, K., Inaba, H., Sakurai, H., Furuyoshi, S., and Tani, N. (2006). "A novel adsorbent of circulating bacterial toxins and cytokines: The effect of direct hemoperfusion with CTR column for the treatment of experimental endotoxemia," Crit. Care Med. 34, 800-806. 
Weber, C., Henne, B., Loth, F., Schoenhofen, M., and Falkenhagen, D. (1995).

"Development of cationically modified cellulose adsorbents for the removal of endotoxins," ASAIO J. 41, M430-M434.

Weber, V., Linsberger, I., Rossmanith, E., Weber, C., and Falkenhagen, D. (2004a).

"Pyrogen transfer across high- and low-flux hemodialysis membranes," Artif. Organs. 28, 210-217.

Weber, W., Rimann, M., Schafroth, T., Witschi, U., and Fussenegger, M. (2006).

"Design of high-throughput-compatible protocols for microencapsulation, cryopreservation and release of bovine spermatozoa," J. Biotechnol. 123, 155-163.

Weber, W., Rinderknecht, M., Daoud-El Baba, M., de Glutz, F. N., Aubel, D., and Fussenegger, M. (2004b). "CellMAC: A novel technology for encapsulation of mammalian cells in cellulose sulfate/pDADMAC capsules assembled on a transient alginate/Ca2+ scaffold," J. Biotechnol. 114, 315-326.

Woffindin, C., Hoenich, N. A. (1988). "Blood-membrane interactions during haemodialysis with cellulose and synthetic membranes," Biomaterials 9, 53-57.

Yao, Q., Axelsson, J., Stenvinkel, P., and Lindholm, B. (2004). "Chronic systemic inflammation in dialysis patients: An update on causes and consequences," ASAIO J. 50, lii-lvii.

Zhou, H. Y., Chen, X. G., Liu, C. S., Meng, X. H., Yu, L. J., Liu, X. Y., and Liu, N. (2005). "Chitosan/cellulose acetate microspheres preparation and ranitidine release in vitro," Pharm. Dev. Technol. 10, 219-225.

Article submitted: July 9, 2006; First review cycle completed: Sept. 14, 2006; Revision accepted: Nov. 20, 2001; Article published: Nov. 24, 2006. 